\title{
Rebound iritis with a well-circumscribed anterior chamber fibrin mass after uncomplicated cataract surgery
}

\author{
Nilesh Raval' ${ }^{*}$, Wen-Jeng (Melissa) Yao, Gene Kim and Joann J. Kang
}

\section{To the editor}

We report a case of subacute rebound iritis characterized by a globular, pedunculated anterior chamber mass that resolved after topical steroid burst.

\section{Case report}

A 59-year-old female with no significant past ocular history underwent cataract extraction (CE) with phacoemulsification and posterior chamber intraocular lens (PCIOL) insertion in the right eye (OD). Intraoperatively, a Malyugin ring was deployed due to poor dilation, however the remainder of the surgery was uneventful. On the first postoperative day, $3+$ mixed cell and pigment in the anterior chamber $(\mathrm{AC})$ without fibrin reaction was observed, which resolved by the second week with topical steroid administration. The patient was lost to follow up and was non-compliant with her steroid taper.

Eight weeks later, the patient presented with eye pain OD. Visual acuity (VA) was 20/40 and intraocular pressure (IOP) by Goldmann applanation was 6; there was no relative afferent pupillary defect (rAPD) noted. Slit lamp biomicroscopy was remarkable for trace Descemet's folds (DF), 3+ mixed AC cell and pigment, and a sharplycircumscribed, globular, partially opaque anterior chamber mass with smooth borders and a well-demarcated stalk attached to the surface of the PCIOL (Fig. 1A and B). The PCIOL was well-centered and dilated fundus examination was unremarkable.
The patient was started on prednisolone acetate $1 \%$ eye drops every two hours and cyclopentolate $1 \%$ eye drops twice a day. Examination three days later showed complete resolution of the mass (Fig. 2A and B) and improvement in $\mathrm{AC}$ inflammation to $1+$ cell. The patient endorsed improvement in her symptoms and was discharged on a tapering regimen of topical steroids but was again lost to follow-up.

\section{Discussion}

The post-operative anterior segment mass reported above most likely represents a fibrinous exudate secondary to rebound iritis. Rebound and persistent iritis are well-known entities that may occur after cataract surgery. Neatrour et al [1] reported that pupil expansion devices significantly increase the risk of persistent $(>1$ month) post-operative iritis.

Fibrinous exudates are occasionally encountered after intraocular surgery, more commonly after pars plana vitrectomy [2-5]. Fibrin reaction has also been reported after anterior segment surgery involving iris manipulation in patients on long-term miotic therapy and in uveitic patients [4]. Following routine cataract surgery, Miyake et al [6] reported a $4.4 \%$ overall incidence of pupillary fibrin membrane formation in Japanese patients, typically around postoperative day five.

\footnotetext{
* Correspondence: nraval@montefiore.org

Department of Ophthalmology, Albert Einstein College of Medicine

Montefiore Medical Center, 3332 Rochambeau Ave, 3rd Floor, Bronx, NY 10467, USA
} 


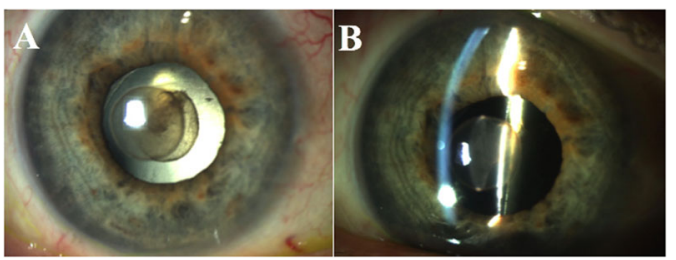

Fig. 1 Sharply-circumscribed, globular, partially opaque mass with a round, smooth border and a well-demarcated stalk attached to the anterior surface of the $\mathrm{PCIOL}$ in retro-illumination $(\mathbf{A})$ and direct illumination (B)

The pathophysiology of post-operative fibrin clots is thought to be secondary to a transient lowering of IOP and disruption in the blood-aqueous barrier during $\mathrm{CE}$, resulting in leakage of fibrinogen-rich fluid from arterial plasma into the $\mathrm{AC}$, eliciting a fibrinoid reaction [7-9]. If untreated, this fibrin can consolidate and result in a dense pupillary membrane. The low IOP seen in this patient was likely secondary to ciliary body shutdown in the setting of anterior uveitis.

To the best of our knowledge, this is the first report in the ophthalmic literature of a subacute post-operative anterior uveitic mass in such a wellcircumscribed configuration that completely resolved after a short course of topical steroids. We surmise that this mass represents a fibrinous exudate in the setting of rebound iritis after cataract surgery involving a pupil expansion device. Ophthalmologists should be aware of this unique presentation after intraocular surgery.

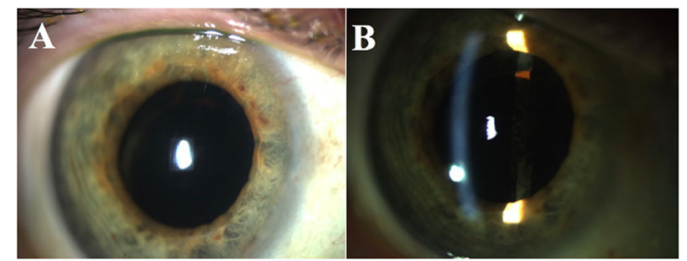

Fig. 2 Complete resolution of the AC mass after three days of topical steroids (A, B)

\section{Abbreviations}

CE: Cataract extraction; PCIOL: Posterior chamber intraocular lens; OD: Right eye; AC: Anterior chamber; VA: Visual acuity; IOP: Intraocular pressure; rAPD: relative afferent pupillary defect; DF: Descemet's folds

\section{Acknowledgements}

We would like to acknowledge Montefiore ophthalmic technicians Kevin Ellerbe and Diana Iglesias for capturing the slit lamp photos presented in this case study.

\section{Authors' contributions}

WY evaluated the patient during the initial post-operative visits. NR and JK worked together to diagnose and provide treatment for the patient during the acute phase. NR compiled the images and was primary author of the case report. GK provided additional consultation during the write-up. All authors read and approved the final manuscript.

\section{Funding}

This research is supported by gifts from Lewis Henkind, as well as the Irving and Branna Sisenwein Endowment Fund to the Department of Ophthalmology, Montefiore Medical Center.

Availability of data and materials Not applicable.

\section{Declarations}

Ethics approval and consent to participate Not applicable.

\section{Consent for publication}

Written informed consent for publication of their clinical details and/or clinical images was obtained from the patient. A copy of the consent form is available for review by the Editor of this journal.

\section{Competing interests}

The authors declare that they have no competing interests.

Received: 25 July 2021 Accepted: 22 September 2021

Published online: 12 October 2021

\section{References}

1. Neatrour K, McAlpine A, Owens TB et al (2019) Evaluation of the etiology of persistent iritis after cataract surgery. J Ophthal Inflamm Infect 9(1):4

2. Jaffe GJ, Schwartz D, Han DP, Gottlieb M, Hartz A, McCarty D, Mieler WF, Abrams GW (1990) Risk factors for postvitrectomy fibrin formation. Am J Ophthalmol 109(6):661-667. https://doi.org/10.1016/S0002-9394(14)72434-1

3. Sebestyen JG (1982) Fibrinoid syndrome: a severe complication of vitrectomy surgery in diabetics. Ann Ophthalmol 14(9):853-856

4. Lesser GR, Osher RH, Whipple D, Abrams GW, Cionni R (1993) Treatment of anterior chamber fibrin following cataract surgery with tissue plasminogen activator. J Cataract Refract Surg 19(2):301-305. https://doi.org/10.1016/50886-3350(13)80961-3

5. Lewis H, Han D, Williams GA (1987) Management of fibrin pupillary block glaucoma after pars plana vitrectomy with intravitreal gas injection. Am J Ophthalmol 103(2):180-182. https://doi.org/10.1016/50002-9394(14)74223-0

6. Miyake K, Maekubo K, Miyake Y, Nishi O (1989) Pupillary fibrin membrane: a frequent early complication after posterior chamber lens implantation in Japan. Ophthalmology. 96(8):1228-1233. https://doi.org/10.1016/S0161-6420(89)32746-1

7. Siatiri H, Beheshtnezhad AH, Asghari H, Siatiri N, Moghimi S, Piri N (2005) Intracameral tissue plasminogen activator to prevent severe fibrinous effusion after congenital cataract surgery. Br J Ophthalmol 89(11):14581461. https://doi.org/10.1136/bjo.2005.071407

8. Wu TT, Wang HH (2009) Intracameral recombinant tissue plasminogen activator for the treatment of severe fibrin reaction in endophthalmitis. Eye. 23(1):101-107. https://doi.org/10.1038/sj.eye.6702984

9. Da Rocha LB, Pichi F, Nucci P, Srivastava SK, Lowder CY (2014) Fibrin reaction after Uveitic cataract surgery: treatment and prevention. Eur J Ophthalmol 24(4):626-628. https://doi.org/10.5301/ejo.5000442

\section{Publisher's Note}

Springer Nature remains neutral with regard to jurisdictional claims in published maps and institutional affiliations. 